\title{
Comparative Analysis of Bilayered and Direct Restorations In Class V Lesions: A Retrospective Study
}

\author{
Research Article
}

Swathi UB ${ }^{1}$, Sindhu Ramesh ${ }^{2 *}$, Delphine Priscilla Antony $S^{3}$

\begin{abstract}
${ }^{1}$ Department of Conservative Dentistry and Endodontics, Saveetha Dental College and Hospitals, Saveetha Institute of Medical and Technical Sciences(SIMATS), Saveetha University, Chennai 600 077, Tamil Nadu, India.

${ }^{2}$ Professor, Department of Conservative Dentistry and Endodontics, Saveetha Dental College and Hospitals, Saveetha Institute of Medical and Technical Sciences(SIMATS), Saveetha University, Chennai 600 077, Tamil Nadu, India.

${ }^{3}$ Senior Lecturer, Department of Conservative Dentistry and Endodontics, Saveetha Dental College and Hospitals, Saveetha Institute of Medical and Technical Sciences(SIMATS), Saveetha University, Chennai 600 077, Tamil Nadu, India.
\end{abstract}

\section{Abstract}

Composite Resins are the most commonly used tooth coloured restorative materials. However, these materials undergo contraction during curing which result in shrinkage of the material. The usage of glass ionomer cement and composite is called as the "Sandwich restoration" and has been proposed to improve marginal adaptation of composite resin and bonding agents.The purpose of this retrospective study was to evaluate the usage of bilayered and direct composite restorations in class V lesions. This retrospective Study,was based on patient records collected from Saveetha Dental College, Chennai. Data collected consisted of 1721 cases in which the type of restoration used for restoration of Class V lesions over a period of one year was evaluated based on the patient's age, gender and tooth in which the restoration was done. In this retrospective study it was observed that there was a significant difference between the type of restoration selected for restoration of Class V lesions $(\mathrm{P}$ value $>0.5)$. Direct restorations of Class V lesions were preferred in majority of the cases (87\%) followed by usage of bilayered restorations in $13 \%$ of the overall cases evaluated. Based on the results on this study, direct restorations are the most preferred technique for restoration of Class V lesions. Bilayered restorations were used in a minimal number of cases in this retrospective study. Bilayered technique could be more advantageous when compared to composite or glass ionomer cement restorations are used alone, especially when gingival margins are examined.

Keywords: Bilayered Restoration; Composite Restoration; Class V Lesions; Direct Restoration; Sandwich Technique.

\section{Introduction}

Restorative management of non-carious cervical lesions presents a special challenge due to their histology glass ionomer cement and structural features. Main etiology glass ionomer cement al factors for these lesions are erosion, abrasion and abfraction. The margins of non cervical carious lesions maybe located in the enamel,cementum or dentin. When these lesions involve the pulp patients may experience pain and require need for root canal treatment [1-4]. Microorganisms have been established as the sole entity responsible for initiating pulpal and periapical pathologies $[5,6]$. Efficiency of the diagnostic aids an important role in the treatment plan $[7,8]$. Dentin hypersensitivity is one of the com- mon problems and the success of treating dentinal hypersensitivity depends on the long term efficiency of treatment modalities [9, 10]. CPP-ACP can be considered as materials of choice for remineralizing early enamel carious lesions [11]. It is very important to be able to properly diagnose a case as it has a huge impact on the success of the treatment $[12,13]$.

Many studies have evaluated usage of resin composites and glass ionomer cements as promising materials for management of these lesions [14, 15]. Glass ionomer cement based materials are clinically popular in several different areas of restorative dentistry as liners as well as luting agents, for core build up and for restorations [16]. Glass ionomer cements have low shrinkage and are

\author{
*Corresponding Author: \\ Sindhu Ramesh, \\ Professor, Department of Conservative Dentistry and Endodontics, Saveetha Dental College and Hospitals, Saveetha Institute of Medical and Technical Sciences(SIMATS), \\ Saveetha University, Chennai 600 077, Tamil Nadu, India. \\ Tel: 9840136543 \\ E-mail: sindhuramesh@saveetha.com \\ Received: October 10, 2019 \\ Accepted: December 04, 2019 \\ Published: December 08, 2019 \\ Citation: Swathi UB, Sindhu Ramesh, Delphine Priscilla Antony S. Comparative Analysis of Bilayered and Direct Restorations In Class V Lesions: A Retrospective Study. Int J \\ Dentistry Oral Sci. 2019;S2:02:0013:60-65. doi: http://dx.doi.org/10.19070/2377-8075-SI02-020013
}

Copyright: Sindhu Ramesh ${ }^{\circ}$ 2019. This is an open-access article distributed under the terms of the Creative Commons Attribution License, which permits unrestricted use, distribution and reproduction in any medium, provided the original author and source are credited. 
thermally compatible to the tooth structure. They can even bond to the dentin structure without removal of the smear layer,glass ionomer cement compatibility is well proved and hence they can be effectively used as lining materials [17]. As a restorative material glass ionomer cement bond to the enamel and dentin via ionic and polar bonds and the intimate molecular contact facilitates ion exchange of fluoride within hydroxyl ions in apatite of surrounding enamel $[18,19]$. Glass ionomer cements maintain adhesion for long periods and are materials of choice to be used in cervical area of the teeth where no cavity prepared is contemplated. According to Hanaoka et al., [20], restorative materials used at the cervical region of the teeth are frequently subjected to resultants of occlusal loads and hence should present biomechanical features capable of resisting under tension which is a peculiar feature of glass ionomer cement. Composites have been preferred due to their improved esthetic properties, improved adhesive capacity, modern dentin adhesives, and increased mechanical properties [21].

An important aspect to be considered when selecting the restorative material for non carious cervical lesions is the materials capacity to partially absorb tension generated during loading distribution through the teeth $[22,23]$. Long-term retention of the tooth and resistance to fracturing are directly related to the amount of residual tooth structure [24]. Veneers can be considered as a minimal invasive option for the treatment of discoloured and malformed teeth with minimal loss of tooth structure in the anterior region [25]. Glass ionomer cements are very durable in cervical restorations and compete with composites where bonding to the cervical dentin is required.New materials such as hybrid materials present improved setting characteristics over conventional glass ionomer cement, sufficiently long working time, rapid development of early strength which in turn renders the matrix less intolerant to effects of moisture [26-29]. The translucency of resin modified glass ionomer cement is better than that of the conventional glass ionomer cement and there is apparent improvement in adhesion to suitable prepared dentin surface.26 These materials can bond directly to composite resin and are well indicated for sandwich technique [30].

In the sandwich technique, glass ionomer cement is sandwiched between the tooth surface and another restorative material above which is usually composite resin [31,32]. This approach combines good properties of glass ionomer cement with those of composite resin and is a recommended technique for restoration. The purpose of this study was to evaluate the preference of direct and bilayered restorations beneath Class V restorations.

\section{Materials and Methods}

\section{Study Design}

Single centered retrospective study.

\section{Ethical Approval}

Approval for the project was obtained from the Institutional Review Board of Saveetha Institute of Medical and Technical Sciences, Chennai, India on Date 18/04/2020. Ethical approval No -SDC/SIHEC/2020/DIASDATA/0619-0320.

\section{Eligibility Criteria}

Inclusive criteria: Included patients of age group of 18 to 60 years, patients with class $\mathrm{V}$ lesions, type of restorative technique used for class $\mathrm{V}$ lesions, permanent teeth.

Exclusive criteria: Consisted of patients of age group more than 60 years, primary teeth, lesions apart from class $\mathrm{V}$, and root canal treated teeth.

\section{Data Extraction}

This retrospective study was based on patient records collected from Saveetha Dental College Chennai from the year June 2019 to March 2020. Retrospective. Data was collected based on the type of restorative technique used in class $\mathrm{V}$ lesions. The final data was exported to excel and saved on a secure server for analysis.

\section{Sample Size}

A total of 9343 clinical cases were evaluated based on the type of restorative technique used in class $\mathrm{V}$ lesions. Out of 9343 cases evaluated 1721 cases were taken taken into account based on the inclusion and exclusion criteria. Data was derived from patient records obtained from Saveetha Dental College, Chennai within the time frame of 10th June 2019 to 1st March 2020.

\section{Groups}

Types of restorative technique used for restoration of class V lesions were divided into two groups.

\section{Group A: Bilayered restoration}

Group B: Direct restoration

\section{Clinical Outcome}

Success rate is assessed based on patient visit after restoration because of pain or difficulty during mastication. All patients were followed up to note the clinical performance of the restoration.

\section{Clinical Protocol}

The clinical protocol for patients undergoing restorative procedures is to access the pulp status by pulp vitality tests, clinical and radiographic findings. After diagnostic procedures, caries excavation is done and decides whether direct or bilayered restorations are needed. Direct restorations involve placement of single restorative material such as composite resin or glass ionomer cement. In Bilayered restorations one restorative material is sandwiched between the tooth surface and another restorative material.

\section{Study Outcome}

Success rate is assessed based on patient visits because of pain, improper contour and contacts after the restorative procedure.In both direct and bilayered restoration patients reported back mainly because of discomfort during mastication and adjustments were made by reducing high points. Post operative sensitivity also affects the success rate. 


\section{Statistical Analysis}

Data entry was done using Microsoft Excel sheet and converted to SPSS software 20.0. Chi-square test was used for statistical analysis between the two types of restorative techniques used for restoration of Class V lesions. Age, gender of the patient was considered as independent variables. Tooth in which the restoration of the class $\mathrm{V}$ lesions was done and the restorative technique used were considered as dependent variables for statistical analysis.

\section{Results and Discussion}

The clinical data base system resulted in a total of 9343 patients charts, identifying the type of restorative technique used for restoration of class $\mathrm{V}$ lesions in patients over a period of one year. After applying the inclusion and exclusion criteria, around 1721 cases met with the criteria.

The data after applying the inclusion and exclusion criteria consisted of 222 cases of bilayered restorations and 1499 cases of direct restoration (Figure 1). With a total of 1721 cases,466 were females and 1255 males (Table 1). Age group of 18-30 years accounted $6.3 \%$ overall cases,age group of $31-40$ years accounted $15.3 \%$ overall cases, age group of $41-50$ years and $51-60$ years ac- counted $39 \%$ and $39.3 \%$ of overall cases (Table 2 ). Of the cases evaluated $12.9 \%$ of cases included bilayered restorations and $87 \%$ included direct restorations (Table 3).

Based on the tooth in which the restoration was done, included $61.8 \%$ maxillary teeth and $38.2 \%$ mandibular teeth of which $22.5 \%$ were anterior teeth and $77.5 \%$ were posterior teeth (Table 4). Based on the tooth type $5.1 \%$ included central incisors, $4.8 \%$ included lateral incisors, $22.4 \%$ included canines, $52.9 \%$ were premolars and $14.8 \%$ were molars (Table 5).

Based on the age and tooth in which the restoration was done maximum cases accounted for use of direct restorations in comparison with bilayered restoration (Figure 2)(Figure 3). According to the results of this retrospective study, direct restorations were preferred over Bilayered restorations for restoration of class $\mathrm{V}$ lesions in the majority of the cases $(87 \%)$.

Various etiologies, locations and structural characteristics make non carious cervical lesions more challenging to adhesive restorative procedures and marginal seal. These lesions are usually multifactorial and acquire unique characteristics that result in a very complex differential diagnosis and a challenging restorative treatment [33]. Composite resin and glass ionomer cements have been indicated as restorative materials of choice for these lesions [34,

Figure 1. Shows total number of cases and cases included based on the inclusion and exclusion criteria.

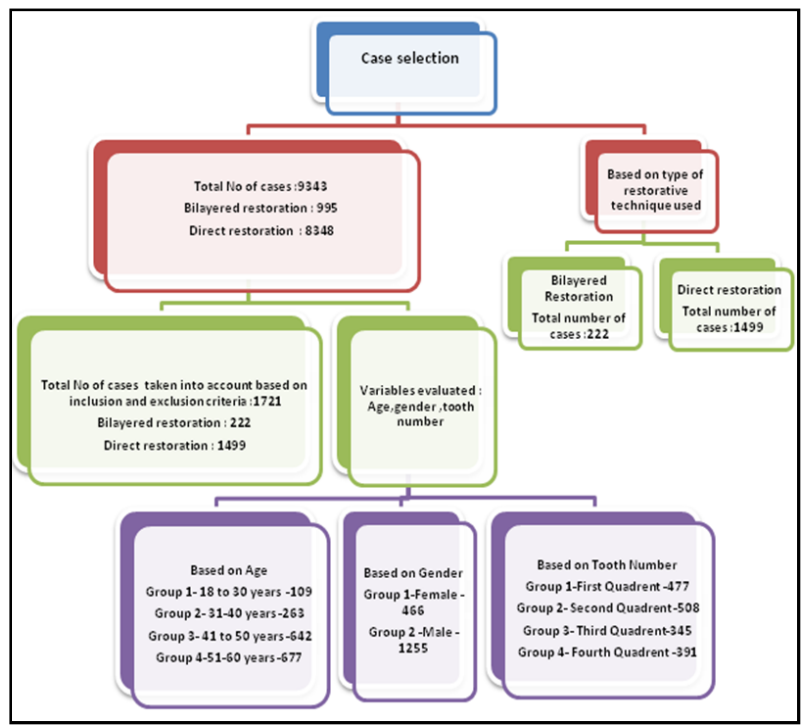

Table 1. Patient Demographics.

\begin{tabular}{|c|c|c|}
\hline Patients Characteristics & No of Patients & Percentage \\
\hline \multicolumn{3}{|c|}{ Gender } \\
\hline Male & 1255 & 72.9 \\
\hline Female & 466 & 27.1 \\
\hline
\end{tabular}

Table 2. Patient Demographics.

\begin{tabular}{|c|c|c|}
\hline \multicolumn{3}{|c|}{ Age } \\
\hline 18- 30 years & 109 & 6.3 \\
\hline 31- 40 years & 263 & 15.3 \\
\hline 41-50 years & 672 & 39 \\
\hline 51-60 years & 677 & 39.3 \\
\hline
\end{tabular}


Table 3. Distribution of type of restorative technique used.

\begin{tabular}{|c|c|c|}
\hline \multicolumn{3}{|c|}{ Type of restoration } \\
\hline Bilayered & 222 & 12.9 \\
\hline Direct restoration & 1499 & 87.1 \\
\hline
\end{tabular}

Table 4. Tooth Distrubution.

\begin{tabular}{|c|c|c|}
\hline Tooth Distribution & No of Teeth & Percentage value \\
\hline \multicolumn{3}{|c|}{ Jaw } \\
\hline Maxillary & 1064 & 61.8 \\
\hline Mandibular & 657 & 38.2 \\
\hline \multicolumn{3}{|c|}{ Teeth Number } \\
\hline Anterior & 387 & 22.5 \\
\hline Posterior & 1334 & 77.5 \\
\hline
\end{tabular}

Table 5. Disturbution of the Tooth type in which the restorative technique was done.

\begin{tabular}{|c|c|c|}
\hline \multicolumn{3}{|c|}{ Teeth Type } \\
\hline Central Incisors & 89 & 5.1 \\
\hline Lateral Incisors & 82 & 4.8 \\
\hline Canine & 387 & 22.4 \\
\hline Premolars & 910 & 52.9 \\
\hline Molars & 253 & 14.8 \\
\hline
\end{tabular}

Figure 2. Graph showing association between age and type of restoration used in class v lesions. Age group of 18-30 years accounted for more cases of bilayered restoration in comparison with direct restoration. Chi square test (14.25 )was done and association was found to be not statistically significant. Pearson's Chi square $P$ value $0.697>0.05$.

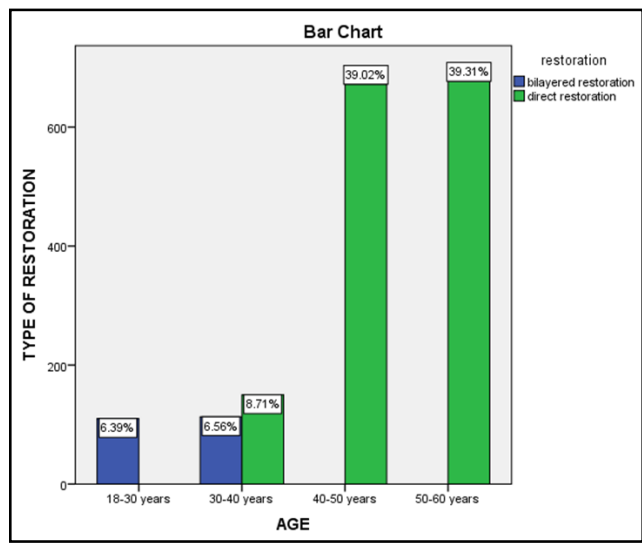

Figure 3. Graph showing association between the tooth in which the restoration is done and the type of restoration. maximum cases accounted of direct restoration and lesser cases of bilayered restorations.Chi square test (44.68)was done and association was found to be not statistically significant. Pearson's Chi square P value $0.476>0.05$.

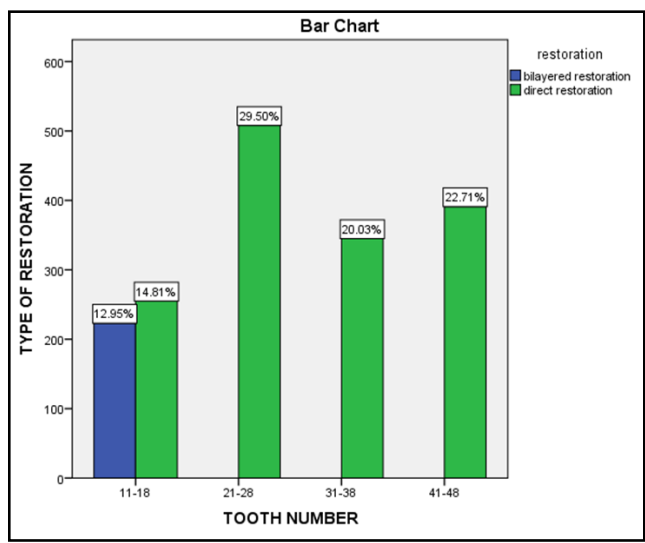


35]. Along with lack of mechanical retention difficulty to control moisture contamination, the longevity and marginal seal are challenging in these lesions.

Glass ionomer cements are very durable in cervical restorations and compete with composites particularly where bonding to the cervical dentin is required.Sclerosed dentin remains the greatest obstacle to obtain bonding with dentin bonding agents and failure that occurs at cervical margin as a result of microleakage is not always detected [17]. Removal of the outer surface layer of sclerotic dentin by roughening with a diamond bur did not improve retention for RMGIC [36]. Several other studies have also proved the same aspect $[37,38]$. Evaluation of non carious cervical lesions restored with glass ionomer cement showed long term retention in comparison to resin based adhesive systems [39]. Compatibility between thermal expansion coefficients from tooth structure and from glass ionomer cement makes mechanical retention unnecessary and saves the remaining tooth structure [40].

RMGIC showed better marginal adaptation to cavity walls when compared to chemical setting glass ionomer cement [41]. Advantages such as improved bond strength ,better physical properties, better polishing,wider colour change and translucency were obtained with the advent of dual cured cements and increased clinical success of class $\mathrm{V}$ restorations [42]. Resin modified glass ionomer cement have good retention results, reduced superficial degradation and increased wear resistance when compared to conventional glass ionomer cement. glass ionomer cement adhere chemically to the tooth structure allied with their coefficient of thermal expansion similar to the tooth structure contributing to better quality and longevity of restorations, especially in missing enamel margins common in non-carious cervical lesions. A five year evaluation of Athens clinical performance of RMGIC was found to be superior to that of composite resin restorations [43].

Studies have shown that the sandwich technique could be advantageous when compared to Composite or glass ionomer cement restorations alone, especially when gingival margins were examined [44]. Disadvantages of this technique include increase of time, complexity and precision requirement to place the restorative materials [42]. However using this approach good properties of glass ionomer cement (adhesion, fluoride release, biocompatibility, thermal expansion, coefficient similar to that of the tooth structure) can be combined with those of composite resins (mechanical resistance, superficial smoothness, Esthetics, great colour stability) $[27,30]$.

\section{Conclusion}

Within the limitations of the study it was concluded that, direct restorations are preferred over bilayered restorations for restoration of Class V lesions in the majority of the cases. Direct restorations provide better esthetics in comparison to Bilayered restorations that require increased time, complexity, precision that is required for the placement of restorations.

\section{Acknowledgment}

With sincere gratitude, we acknowledge the staff members of the department of Conservative Dentistry and Endodontics, Saveetha Dental College and study participants for their extended support towards the completion of research.

\section{Study Limitation}

The study cannot be generalised to a larger population due to the minimal sample size. Future research should be recommended for the usage of sandwich technique and its longevity in restoration of class $\mathrm{V}$ lesions with use of a larger sample size.

\section{Future Scope}

Bilayered / sandwich technique should be recommended for restoration of class $\mathrm{V}$ Lesions as it combines good properties of glass ionomer cement such as adhesion, fluoride release, biocompatibility, thermal expansion, coefficient similar to that of the tooth structure combined with those of composite resins such as mechanical resistance, superficial smoothness, Esthetics and great colour stability.

\section{References}

[1]. Teja KV, Ramesh S. Shape optimal and clean more. Saudi Endod. J. 2019 Sep $1 ; 9(3): 235$.

[2]. Noor S. Chlorhexidine: Its properties and effects. Res J Pharm Technol. 2016;9(10):1755-60.

[3]. Manohar MP, Sharma S. A survey of the knowledge, attitude, and awareness about the principal choice of intracanal medicaments among the general dental practitioners and nonendodontic specialists. Indian J Dent Res. 2018 NovDec;29(6):716-720.Pubmed PMID: 30588997.

[4]. Kumar D, Antony S. Calcified Canal and Negotiation-A Review. Res J Pharm Technol. 2018;11(8):3727-30.

[5]. Siddique R, Sureshbabu NM, Somasundaram J, Jacob B, Selvam D. Qualitative and quantitative analysis of precipitate formation following interaction of chlorhexidine with sodium hypochlorite, neem, and tulsi. J Conserv Dent. 2019 Jan-Feb;22(1):40-47.Pubmed PMID: 30820081.

[6]. Teja KV, Ramesh S, Priya V. Regulation of matrix metalloproteinase-3 gene expression in inflammation: A molecular study. J Conserv Dent. 2018 Nov;21(6):592-6.

[7]. Janani K, Palanivelu A, Sandhya R. Diagnostic accuracy of dental pulse oximeter with customized sensor holder, thermal test and electric pulp test for the evaluation of pulp vitality: an in vivo study. Braz. Dent. Sci. 2020 Jan 31;23(1):8-p.

[8]. Ramamoorthi S, Nivedhitha MS, Divyanand MJ. Comparative evaluation of postoperative pain after using endodontic needle and EndoActivator during root canal irrigation: A randomised controlled trial. Aust Endod J. 2015 Aug;41(2):78-87.Pubmed PMID: 25195661.

[9]. Janani K, Ajitha P, Sandhya R. Improved quality of life in patients with dentin hypersensitivity. Saudi Endod. J. 2020 Jan 1;10(1):81.

[10]. Nandakumar M, Nasim I. Comparative evaluation of grape seed and cranberry extracts in preventing enamel erosion: An optical emission spectrometric analysis. J Conserv Dent. 2018 Sep-Oct;21(5):516-520.Pubmed PMID: 30294113.

[11]. Rajendran R, Kunjusankaran RN, Sandhya R, Anilkumar A, Santhosh R, Patil SR. Comparative Evaluation of Remineralizing Potential of a Paste Containing Bioactive Glass and a Topical Cream Containing Casein PhosphopeptideAmorphous Calcium Phosphate: An in Vitro Study. Pesqui Bras Odontopediatria Clin Integr. 2019;19.

[12]. Jose J, Subbaiyan H. Different Treatment Modalities followed by Dental Practitioners for Ellis Class 2 Fracture-A Questionnaire-based Survey. Open Dent. J. 2020 Feb 18;14(1).

[13]. Rajakeerthi R, Ms N. Natural Product as the Storage medium for an avulsed tooth-A Systematic Review. Cumhur. Dent. J. 2019;22(2):249-56.

[14]. Santiago SL, Passos VF, Vieira AH, Navarro MF, Lauris JR, Franco EB. Twoyear clinical evaluation of resinous restorative systems in non-carious cervical lesions. Braz. Dent. J. 2010;21(3):229-34.

[15]. Sharafeddin F, Feizi N. Evaluation of the effect of adding micro-hydroxyapatite and nano-hydroxyapatite on the microleakage of conventional and resinmodified Glass-ionomer CI V restorations. Journal of Clinical and Experimental Dentistry 2017:0-0.

[16]. Tyas MJ, Burrow MF. Adhesive restorative materials: a review. Aust. Dent. 2004 Sep;49(3):112-21.

[17]. McLean JW. The clinical use of glass-ionomer cements. Dent Clin North Am. 
1992 Jul;36(3):693-711.

[18]. Billington RW, Pearson GJ, Williams JA. Uptake of fluoride ions by the glass component of glass ionomer cement. J Dent. 2007 May;35(5):452-5.Pubmed PMID: 17196321.

[19]. Powis DR, Follerås T, Merson SA, Wilson AD. Materials science: Improved adhesion of a glass ionomer cement to dentin and enamel. J Dent Res. 1982 Dec;61(12):1416-22.

[20]. Hanaoka K. A biomechanical approach to etiology and treatment of noncarious dental cervical lesions. Bull. Kanagawa Dent. Coll.. 1998;26:103-13.

[21]. Hussainy SN, Nasim I, Thomas T, Ranjan M. Clinical performance of resinmodified glass ionomer cement, flowable composite, and polyacid-modified resin composite in noncarious cervical lesions: One-year follow-up. J Conserv Dent. 2018 Sep-Oct;21(5):510-515.Pubmed PMID: 30294112.

[22]. Heyrnann HO, Bayne SC. Current concepts in dentin bonding; focusing on dentin adhesion factors J Arn Dent AS, 124: 27-36, 1993. 2. Bord) n-Aykroyd S, 3efton J, Davies EH: In vitro bond strength of three current dentin adhesives to primary and permanent teeth. Dent Mater 1992:8274-8.

[23]. Yap AU, Neo JC. Non-carious cervical tooth loss. Part 2: Management. Dent Update. 1995 Nov;22(9):364-8.Pubmed PMID: 8948224.

[24]. Ramanathan S, Solete P. Cone-beam Computed Tomography Evaluation of Root Canal Preparation using Various Rotary Instruments: An in vitro Study. The J Contemp Dent Pract. 2015 Nov 1;16(11):869-72.

[25]. Ravinthar K. Recent advancements in laminates and veneers in dentistry. Res J Pharm Technol. 2018;11(2):785-7.

[26]. Nicholson JW, Czarnecka B. The biocompatibility of resin-modified glassionomer cements for dentistry. Dent Mater. 2008 Dec 1;24(12):1702-8.

[27]. Smith DC. Development of glass-ionomer cement systems. Biomaterials. 1998 Apr 1;19(6):467-78.

[28]. Syrek A. Features of modern glass ionomers and their relevance to clinical practice. J Dent. 2006 Sep 1;34(8):615-6.

[29]. Wilson AD. Resin-modified glass-ionomer cements. Int J Prosthodont. 1990 Sep 1;3(5):425-9.

[30]. Croll TP. The" sandwich" technique. J Esthet Restor Dent 2004;16:210-2.

[31]. Berg JH. Glass ionomer cements. Pediatr Dent. 2002 Sep;24(5):430-8.

[32]. Rao V, Reddy VV. An in vitro comparative evaluation of the tensile bond strength at the two interfaces of the sandwich technique. J Indian Soc Pedod Prev Dent. 1995 Aug;13(1):10-2.Pubmed PMID: 9522732.
[33]. Lambrechts P, Van Meerbeek B, Perdigao J, Gladys S, Braem M, Vanherle G. Restorative therapy for erosive lesions. Eur J Oral Sci. 1996 Apr;104(2):229 40

[34]. Ozgünaltay G, Onen A. Three-year clinical evaluation of a resin modified glass-ionomer cement and a composite resin in non-carious class $\mathrm{V}$ lesions. J Oral Rehabil. 2002 Nov;29(11):1037-41.Pubmed PMID: 12453256.

[35]. Powell LV, Gordon GE, Johnson GH. Clinical evaluation of direct esthetic restorations in cervical abrasion/erosion lesions: one-year results. Quintessence Int. 1991 Sep;22(9):687-92.Pubmed PMID: 1835107.

[36]. van Dijken JW. Retention of a resin-modified glass ionomer adhesive in noncarious cervical lesions. A 6-year follow-up. J Dent. 2005 Aug;33(7):541-7. Pubmed PMID: 16005793.

[37]. van Dijken JW. Clinical evaluation of three adhesive systems in class V non-carious lesions. Dent Mater. 2000 Jul;16(4):285-91.Pubmed PMID: 10831784.

[38]. van Dijken JW. Durability of three simplified adhesive systems in Class V noncarious cervical dentin lesions. Am J Dent. 2004 Feb;17(1):27-32.Pubmed PMID: 15241906.

[39]. van Dijken JW. Four-year evaluation of the effect of $10 \%$ polyacrylic acid or water rinsing pretreatment on retention of glass polyalkenoate cement. Eur J Oral Sci. 1996 Feb;104(1):64-6.Pubmed PMID: 8653499.

[40]. Summitt JB, Robbins JW, Hilton TJ, Schwartz RS, Dos Santos J Jr. Fundamentals of operative dentistry: a contemporary approach. Quintessence Pub. Chicago; 2006.

[41]. Sidhu SK. Marginal contraction gap formation of light-cured glass ionomers. Am J Dent. 1994 Apr;7(2):115-8.Pubmed PMID: 8054184.

[42]. Tyas MJ. The Class V lesion--aetiology and restoration. Aust Dent J. 1995 Jun;40(3):167-70.Pubmed PMID: 7661762

[43]. Franco EB, Benetti AR, Ishikiriama SK, Santiago SL, Lauris JR, Jorge MF, et al. 5-year clinical performance of resin composite versus resin modified glass ionomer restorative system in non-carious cervical lesions. Oper Dent. 2006 Jul-Aug;31(4):403-8.Pubmed PMID: 16924979.

[44]. Kovarik RE, Haubenreich JE, Gore D. Glass ionomer cements: a review of composition, chemistry, and biocompatibility as a dental and medical implant material. J Long Term Eff Med Implants. 2005;15(6):655-71.Pubmed PMID: 16393133. 